\title{
Correction to: An analytical interface shape approximation of microscopic Taylor flows
}

\author{
Ulrich Mießner $^{1} \cdot$ Thorben Helmers $^{1} \cdot$ Ralph Lindken $^{2} \cdot$ Jerry Westerweel ${ }^{3}$
}

Published online: 31 May 2019

○) Springer-Verlag GmbH Germany, part of Springer Nature 2019

\section{Correction to: Experiments in Fluids (2019) 60:75 https://doi.org/10.1007/s00348-019-2719-0}

In the original version of the article, the supplementary material was unintentionally omitted. The electronic supplementary material can be accessed through the link below.

Publisher's Note Springer Nature remains neutral with regard tojurisdictional claims in published maps and institutional affiliations.

The original article can be found online at https://doi.org/10.1007/ s00348-019-2719-0.

Electronic supplementary material The online version of this article (https://doi.org/10.1007/s00348-019-2750-1) contains supplementary material, which is available to authorized users.

Ulrich Mießner

miessner@uvt.uni-bremen.de

Thorben Helmers

helmers@uvt.uni-bremen.de

Ralph Lindken

ralph.lindken@hs-bochum.de

Jerry Westerweel

j.westerweel@tudelft.nl

1 Department of Environmental Process Engineering (UVT), University of Bremen, Leobener Str. 6, 28359 Bremen, Germany

2 Institute of Thermodynamics and Fluid Dynamics, Bochum University of Applied Sciences, Lennershofstraße 140, 44801 Bochum, Germany

3 Laboratory of Aero- and Hydrodynamics (AHD), Delft University of Technology, Mekelweg 2, 2628 CD Delft, The Netherlands 